\title{
Lockdown induced change in energy balance
}

\author{
Klaas R. Westerterp ${ }^{1}$
}

Received: 10 April 2021 / Revised: 17 May 2021 / Accepted: 26 May 2021 / Published online: 6 July 2021

(c) The Author(s), under exclusive licence to Springer Nature Limited 2021

The recent Covid-19 pandemic caused countries worldwide to implement measures affecting inhabitants' freedom including a ban on travel and gatherings, instructions to work from home, and a lockdown of restaurants and nonfood shops. Consequently, there were important changes in lifestyle with regard to both, dietary habits and physical activity. Publications on lockdown induced changes in dietary habits, physical activity, and energy balance are available and show significant differences from pre-Covid values.

A review of 23 studies concluded that lockdown resulted in weight gain [1], predominantly from increased screen time and television viewing, associated with an increase in the consumption of comfort foods. A more recent review of 41 studies, reporting the impact of confinement on body mass, confirmed this observation [2]. The latter study of Khan et al. [2] covered a large number of nearly 500,000 participants from more than 35 countries. Weight gain occurred more in participants who were already overweight or obese [2]. A longitudinal study in 727 subjects in the US, during lockdown from April/May to September/October 2020 , observed a mean body mass increase of $0.62 \mathrm{~kg}$ [3]. The authors speculate that, although the lockdown period was short-lived, it placed people at greater risk of longerterm weight gain.

An issue with the data so far is that they were based on self-report through online surveys, which can introduce bias. Moreover, possible causes as changes in dietary habits or changes in physical activity cannot be disentangled. Previously, longitudinal observations, based upon precise measures of body mass, showed a fairly stable body mass, with a mean annual value of $58.4 \mathrm{~kg}$ during the 4 years before the lockdown, while seasonal variation in body mass was fully explained by seasonal variation in physical activity [4]. Continuation of these measurements during the lockdown, which included for the subject of study mainly a reduction of physical activity, shows an unpreceded increase in mean body mass, to a mean value of $59.2 \mathrm{~kg}$. In addition, the annual cycle of daily measured body mass shows a higher minimum and maximum during the last year of observation, with the continuous lockdown restrictions starting in early 2020 in the country of residence of the subject (Fig. 1). This is likely caused by reduced physical activity due to restrictions on travel, and cycling to work, while meeting online and working from home, while energy intake remained the same, resulting in a positive energy balance. The increase in body mass is comparable to the mean increase observed in other largescale online studies.

The question is how to address the lockdown related increase in body mass, when Covid-19 restrictions are lifted? As suggested before, physical activity is rather a function than a determinant of energy balance [5]. The most effective measures to get rid of the gained weight are dietary strategies in order to reduce energy intake [6], despite the fact that the lockdown associated positive energy balance was likely to be related to a reduction of activity-induced energy expenditure.

In a recent systematic review on weight loss and weight control, the most frequently reported dietary strategies for weight loss were: having healthy foods available at home, regular breakfast intake and increasing vegetable consumption [6]. An increase in physical activity will facilitate subsequent maintenance of diet-induced weight loss [6].

Klaas R. Westerterp

k.westerterp@maastrichtuniversity.nl

1 Nutrition and Translational Research in Metabolism (NUTRIM), Maastricht University Medical Centre, Maastricht, The Netherlands 


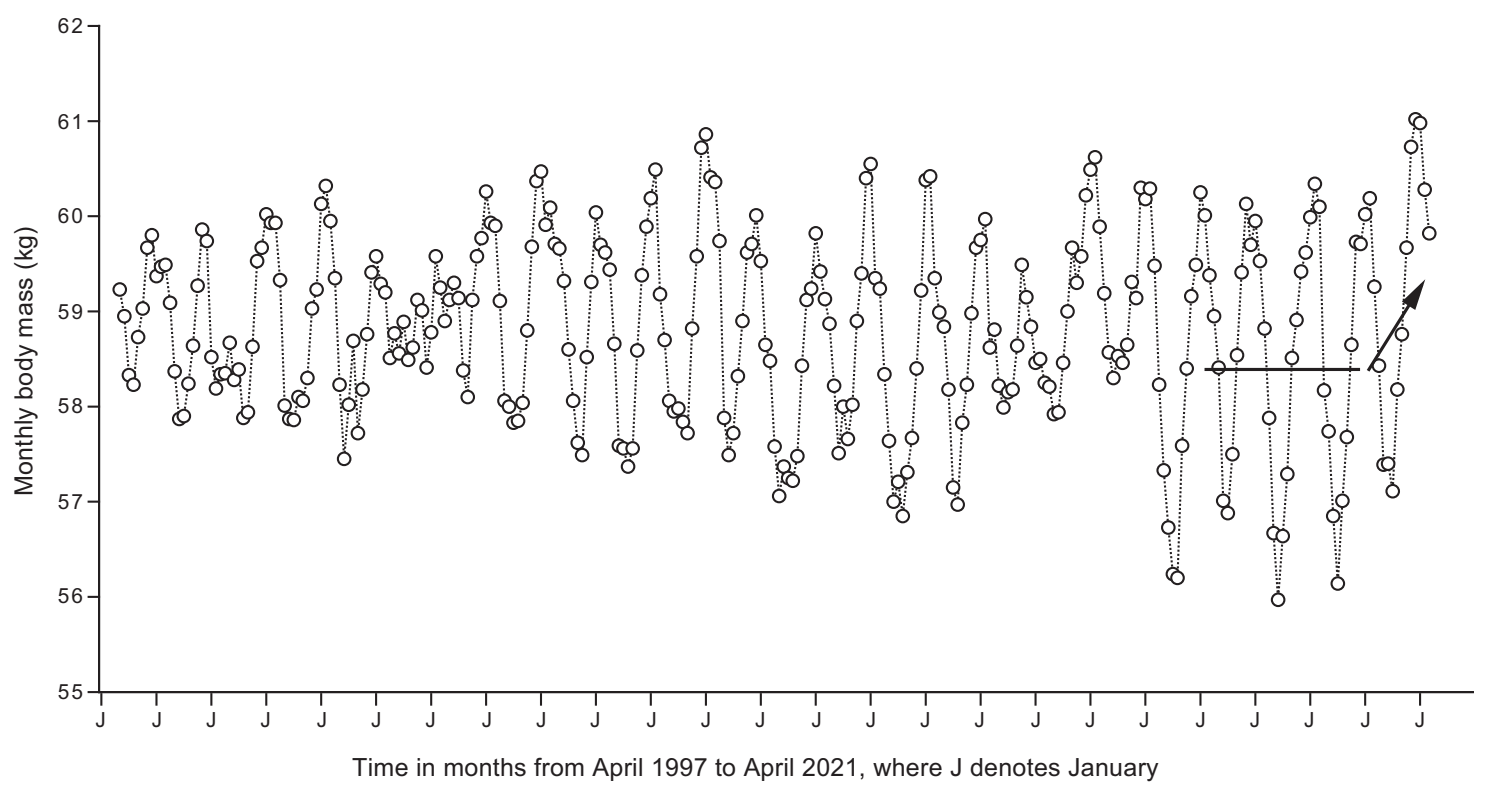

Fig. 1 Monthly measures of body mass (kg) from April 1997 to April 2021 in one subject. $J$ denotes January; the continuous line denotes the mean body mass value over 4 years before lockdown

\section{Compliance with ethical standards}

Conflict of interest KRW is a member of the editorial board of the journal.

Publisher's note Springer Nature remains neutral with regard to jurisdictional claims in published maps and institutional affiliations.

\section{References}

1. Bennett G, Young E, Butler I, Coe S. The impact of lockdown during the Covid-19 outbreak on dietary habits in various population groups: a scoping review. Front Nutr. 2021;8:626432. started; and the arrow denotes the change to the mean value over the year of the lockdown. Partly after reference [4].

2. Khan MAB, Menon P, Govender R, Samra A, Nauman J, Ostlundh $\mathrm{L}$, et al. Systematic review of the effects of pandemic confinements on body weight and their determinants. Br J Nutr 2021;1-74. https://doi.org/10.1017/S0007114521000921.

3. Bhutani S, vanDellen MR, Cooper JA. Longitudinal weight gain and related risk behaviors during the Covid-19 pandemic in adults in the US. Nutrients. 2021;13:671.

4. Westerterp KR. Seasonal variation in body mass, body composition and activity-induced energy expenditure: a long-term study. Eur J Clin Nutr. 2020;74:135-40.

5. Westerterp KR. Physical activity and energy balance. Eur J Clin Nutr. 2019;73:1327-30.

6. Palixao C, Dias CM, Jorge R, Carraca EV, Yannakoulia M, de Zwaan M, et al. Succesful weight loss maintenance: a systematic review of weight control registries. Obes Rev. 2020;21:e13003. 